\title{
Genetic Tools for Pseudomonads, Rhizobia, and Other Gram-Negative Bacteria
}

BioTechniques 32:386-401 (February 2002)

\author{
John Davison \\ Institut National de la \\ Recherche Agronomique \\ (INRA), Versailles, France
}

\begin{abstract}
Gram-negative bacteria are extraordinarily diverse microorganisms that present a wide variety of characteristics worthy of genetic investigation. For historical reasons, the application of recombinant DNA technology to Gram-negative bacteria in general has always lagged behind that of $\mathrm{E}$. coli and its close relatives. However, the past 10 years have seen dramatic advances in the development of new tools and vectors for genetic analysis in non-E. coli hosts. Applications include various kinds of genetic manipulation, conjugation, transposition, site-specific recombination, protein secretion, protein purification, cell suicide, microbial ecology, biodegradation, and plant and animal pathogenicity.
\end{abstract}

\section{INTRODUCTION}

The recombinant DNA revolution began in E. coli in the mid 1970 s and evolved rapidly because the well-studied plasmids (ColE1, p15A, and pSC101) and bacteriophage $\lambda$ needed little modification for use as recombinant DNA vectors. Thus, recombinant DNA technology rapidly produced a wide variety of sophisticated specialpurpose vectors for $E$. coli. On the other hand, recombinant DNA opened up the prospect of performing genetic analyses in a wide variety of other bacteria that present myriad features of scientific, medical, veterinary, agricultural, and biotechnological interest. Among such bacteria are species of the genera Acetobacter, Acinetobacter, Agrobacterium, Alcaligenes, Azotobacter, Bordetella, Bradyrhizobium, Brucella, Burkholderia, Comamonas, Methylobacterium, Paracoccus, Pseudomonas, Ralstonia, Rhizobium, Rhodopseudomonas, Sinorhizobium Sphingomonas, Vibrio, Xanthomonas, and Yersinia. Unfortunately, the narrow-host-range $E$. coli vectors are unable to replicate in most of these bacteria, and alternative cloning systems had to be found. The purpose of the present review is to summarize the state-of-the-art genetic tools for recom binant DNA in Gram-negative bacteria other than E. coli.

\section{GENERAL CLONING VECTORS}

Genetic engineering with Gram-negative bacteria has a number of require- ments that vary in importance according to the specific experimental situation. Table 1 provides useful, generalpurpose plasmid vectors characterized according to their replicon, cloning characteristics, and selective markers.

\section{Replicon}

In general, all vectors need to replicate in the chosen host (major exceptions are transposon vectors and certain promoter-probe vectors, which integrate into the host chromosome). Using broad-host-range replicons as the basis of cloning vector development $(29,31$, 106) has the advantage that the cloning may be performed by standard techniques in $E$. coli, which is easy to manipulate, and the recombinant plasmid is subsequently transferred to different experimental hosts, usually by conjugation. Historically, three main types of broad-host-range replicons have been popular for vector construction: RK2 (IncP), RSF1010 (IncQ), and pSa (IncW). These plasmids are able to replicate in a wide variety of Gram-negative hosts. Indeed, the RSF1010-based, cosmid cloning vector pJRD215 $(27,31)$, though originally constructed for Pseudomonas spp., has also proven useful in most Gram-negative bacteria and some Gram-positives, including Pasteurella multicida, Porphyromonas gingivalis, Actinomyces naeslundii, A. visosus, Thiobacillus ferrooxidans, $M y$ cobacterium aurum $M$. smegmatis, Rhodobacter spheroides, Desulfovibrio vulgaris, Streptomyces lividans, Brevibacterium methylicum, and the marine 
Table 1. General-Purpose Cloning Vectors

\begin{tabular}{|c|c|c|c|}
\hline Cloning Vector & Replicon & Characteristics & Reference \\
\hline pRK310 series & RK2 & $\mathrm{Tc}^{\mathrm{R}}$, lacZ $\alpha, m o b, \operatorname{lnc} \mathrm{P}$ & (43) \\
\hline pLAFR5 & RK2 & $\mathrm{Tc}^{\mathrm{R}}$, mob, mcs, cos, IncP & $(70)$ \\
\hline pRK415 & RK2 & $\mathrm{Km} R$, lacZ $\alpha, m o b, m c s, \operatorname{IncP}$ & (70) \\
\hline pJB3Cm6 series & $\mathrm{RK} 2$ & $\mathrm{Cm} \mathrm{m}^{\mathrm{R}}, \mathrm{Ap}^{\mathrm{R}}$, lacZ $\alpha$, mcs, oriT, IncP & $(15)$ \\
\hline pKT210 series & RSF1010 & $\mathrm{Cm} R, \mathrm{Sm} R, \mathrm{IncQ}$ & $(10)$ \\
\hline pJRD215 & RSF1010 & $\mathrm{Km} R, \mathrm{Sm}^{\mathrm{R}}, \mathrm{mcs}, \mathrm{mob}, \mathrm{cos}$, IncQ & (31) \\
\hline pDSK509 series & RSF1010 & $\mathrm{Km} R$, mcs, mob, IncQ & $(70)$ \\
\hline pUFR027 series & $\mathrm{pSa}$ & $\mathrm{Km} R$, lacZ $\alpha$, mcs, mob, IncW & $(37)$ \\
\hline pBBR1MCS-1 series & pBBR1 & $\mathrm{CmR}$, lacZ $\alpha$, mcs, mob & $(12,41,75,76)$ \\
\hline pUCP18 series & pMB1/pR01614 & $A p^{R}, l a c Z \alpha, m c s$ & $(110,111)$ \\
\hline pVSP41 series & $\mathrm{p} 15 \mathrm{~A} / \mathrm{pVS} 1$ & $\mathrm{Km}$, sta, cos, mcs & $(130)$ \\
\hline pME6010 series & $\mathrm{p} 15 \mathrm{~A} / \mathrm{pVS} 1$ & $\mathrm{TcR}$, sta, mcs, oriT & $(54)$ \\
\hline pRAD1 & pUE10/pMLT23 & $A p^{R}, C^{R}$, lacZ $\alpha, m c s$ & $(86)$ \\
\hline \multicolumn{4}{|c|}{$\begin{array}{l}\text { No attempt is made to list all available cloning vectors. When a series of similar variants is available this is indicated by } \\
\text { "series" in column } 1 \text {. Vectors are grouped according to their replicon. Abbreviations are : TcR, resistance to tetracycline; KmF } \\
\text { resistance to kanamycin; } \mathrm{CmR} \text {, resistance to chloramphenicol; } \mathrm{Ap} \text {, resistance to ampicillin; GmR, resistance to gentamycin } \\
\mathrm{Tp} R \text {, resistance to trimethoprim; } \mathrm{Hy} \text {, resistance to hygromycin; } S p R \text {, resistance to spectinomycin; sta, stability locus; cos, } \\
\text { cosmid (cohesive ends of phage } \lambda \text { ); mcs, multiple cloning site; lacZ } \alpha, \beta \text {-galactosidase complementation; parDE plasmid } \\
\text { maintenance; oriT, origin of transfer; mob, mobilization; functions of RSF1010; inc, incompatibility group. }\end{array}$} \\
\hline
\end{tabular}

cyanobacterium Synechococcus sp.

The RSF1010- and RK2 (RP4)based cloning vectors are typically larger in size than the narrow-hostrange, pMB1-based cloning vectors of E. coli. The size of the RSF1010-based vectors cannot easily be reduced since three genes (rep) plus the origin of replication (oriV) are necessary for the replication, and three mob genes plus the origin of transfer (oriT) are needed for the mobilization (Tables 1-3). In RK2-based vectors, the minimal replicon for replication contains only the ori $V$ and the $\operatorname{trf} A$ genes, but in addition to oriT for conjugal transfer (i.e., when the Tra functions are provided in trans), it is also preferable to include one or more plasmid stabilization functions such as parDE. A more complete understanding of the molecular biology of plasmid RK2 has now permitted the construction of smaller well-defined RK2 vectors $(15,16)$.

More recently, several alternative replicons have also been used for vector construction. A newly discovered broad-host-range plasmid, pBBR1 (from B. bronchioseptica), has the ad- vantage of having a small and stable minimal replicon $(12,41,75,76)$. Similarly, the Pseudomonas plasmid pVS1 is able to replicate in many Gram-negative bacteria but not in E. coli (130). The minimal replicon of $\mathrm{pVS} 1$ was combined with E. coli p15A replicon, thus adding the considerable advantages offered by this host. The resulting plasmids are relatively small in size and are quite stable, even under nonselective conditions (54). Yet another series of vectors is based on replicon pRO1600, which, like VS1, can replicate in many Gram-negative species but not in E. coli. This plasmid was originally thought to be derived from RP1, but recent sequencing of the minimal origin of replication now makes this unlikely. The combination of the minimal origin of pRO1600 with the E. coli pUC18/19 produces vectors able to function in E. coli and in Pseudomonads $(110,135)$.

Deinococcus radiodurans is not related to any bacterium whose genetics are well understood but has proven to be particularly refractile to gene cloning, probably because its promot- ers are not recognized in $E$. coli and visa versa. Double replicon, $D$. radiodurans-E. coli shuttle vectors have been constructed by making hybrids between pBR322-based plasmids and a naturally occurring $D$. radiodurans plasmid pUE10 $(84,86)$.

\section{Incompatibility}

Plasmids are of the same incompatibility group when they cannot be stably maintained in the same host. Conversely, plasmids from different incompatibility groups (Inc), such as incQ, incP, and incW (Table 1), are compatible and may stably co-replicate in the same cell. This can be important when it is desired to supply genetic functions in trans from different plasmids $(27,28)$. It is also useful for the elimination of a resident plasmid, for example, during gene replacement (126).

\section{Conjugation}

Many Gram-negative bacteria are difficult to transform with naked DNA, whereas conjugation is usually quite ef- 
ficient. In most cases, broad-host-range vectors contain an origin of conjugal transfer, usually the oriT of plasmid RK2 or the mob region of RSF1010 $(26,27,106)$. To facilitate vector construction, special cassettes containing the oriT region of plasmid RP4 have been constructed (4). Mobilizable vectors are small and incapable of selftransfer but can be mobilized in the presence of a conjugative plasmid such as RP4. For this purpose, the E. coli strains S17-1 or SM10 (116), which have a chromosomally integrated copy of RP4 able to supply the transfer functions in trans, may be used. In other hosts, a tri-parental mating system using plasmid pRK2013, a ColE1-based plasmid carrying the tra genes of RK2, is employed (106).

\section{Selective Markers}

The cloning vectors all contain antibiotic resistance markers to select plasmid-containing colonies, following transformation or conjugation. Since different bacteria are sensitive to different antibiotics, a given series of plasmid vectors (Table 1) may have a selection of selective markers appropriate to a given host. Numerous cassettes containing antibiotic resistance genes flanked by unique restriction sites have been constructed $(3,5,41,50)$.

\section{Cosmids}

Many broad-host-range cloning vectors contain $\cos$ sites, which are short regions of DNA containing the cohesive ends of phage $\lambda$. These vectors are referred to as cosmids and have the advantage that they can accept large fragments of DNA. Thus, 30-48-kb fragments (depending on the size of the cosmid vector) from a partial digest of chromosomal DNA are ligated to the cosmid vector and efficiently packaged into bacteriophage $\lambda$ particles. These phage particles can then be used to inject the packaged DNA into E. coli, where it replicates as a plasmid. When the E. coli host (e.g., S17-1) carries a RK2 plasmid, the resulting plasmids may then be transferred to another bacterium (e.g., Pseudomonas) by conjugation. This permits the rapid screening of an entire gene bank and selection of

Table 2. Expression Vectors

\begin{tabular}{|c|c|c|c|}
\hline $\begin{array}{l}\text { Expression } \\
\text { Vector }\end{array}$ & Replicon & Characteristics & Reference \\
\hline pVDZ'2 & RK2 & Plac, $\mathrm{Tc}^{\mathrm{R}}$ & (40) \\
\hline pJB864 series & RK2 & $x y / S P m, A p^{R}, m c s$ & $(15,16)$ \\
\hline pCF430 & RK2 & $\operatorname{araC}, P_{B A D} \mathrm{Tc}^{\mathrm{R}}, m c s, m o b$ & (94) \\
\hline pMMB22 series & RSF1010 & lacla, Ptac, $\mathrm{Sm}^{\mathrm{R}}, \mathrm{Ap}^{\mathrm{R}}$ & $(11,92)$ \\
\hline pVDtac39 series & RSF1010 & lacla, Ptac, ApR, mcs & $(40)$ \\
\hline pNM185 & RSF1010 & $x y I S P m, \mathrm{Km} R, S m^{\mathrm{R}}, m c s$ & (87) \\
\hline pML122 & RSF1010 & $P N m, K m^{R}, \mathrm{Tc}^{\mathrm{R}}$ & (78) \\
\hline pML130 & RFS1010 & Plac, $K m^{R}, \mathrm{Tc}^{\mathrm{R}}$ & (78) \\
\hline pJRD215K & RSF1010 & $\lambda c l_{857}, \lambda P_{R}, \mathrm{KmR}, \mathrm{SmR}$, mob & (30) \\
\hline pPLGN1 & RSF1010 & $\lambda c l_{857}, \lambda \mathrm{P}_{L}, \mathrm{Km}^{\mathrm{R}}, \mathrm{Sm}^{\mathrm{R}}$, mob & (80) \\
\hline pJRD253 & RFS1010 & phage $\mathrm{T} 7 \phi 10, \mathrm{Sm} R, \mathrm{mob}$ & (28) \\
\hline pUCPKS & $\mathrm{pMB} 1 / \mathrm{pR} 01614$ & phage $T 7 \phi 10, A p^{R}$, lacZ $\alpha$, mcs & $s \quad(133)$ \\
\hline pJN105 & pBBR1 & $\operatorname{ara} G P_{B A D} \mathrm{Gm}^{\mathrm{R}}, \mathrm{mcs}, \mathrm{mob}$ & $(94)$ \\
\hline pBBad22T series & pBBR1 & $\operatorname{araC}, P_{B A D} \mathrm{Tc}^{\mathrm{R}}, m c s, m o b$ & $(121)$ \\
\hline pBBad22K & pBBR1 & $\operatorname{araC}, P_{B A D} \mathrm{Km}$, mcs, mob & (121) \\
\hline pSPORTn3 & pMB8 & Tn3-based Apr, lac/q, $\mathrm{P}_{\mathrm{lac}}$ & (69) \\
\hline \multicolumn{4}{|c|}{$\begin{array}{l}\text { No attempt is made to list all expression plasmids. When a series of similar } \\
\text { variants is available this is indicated by "series" in column } 1 \text {. Vectors are grouped } \\
\text { according to incompatibility group. Transposon expression vectors are listed } \\
\text { under Table } 3 \text {. Abbreviations are as in Table } 1 \text { except: laclq and Ptac and Plac, } \\
\text { IPTG-responsive regulator and promoters; } x y / S \text { and } P m \text {, alkylbenzoate } \\
\text { responsive regulator and promoter; ara } G \text { and } P_{B A D} \text { arabinose responsive } \\
\text { regulator and promoter; } \lambda c l_{857} \text { and } \lambda P_{R} \text { and } \lambda P_{R} \text {; thermosensitive } \lambda \text { repressor } \\
\text { and promoters; phage T7 } 710, T 7 \text { polymerase responsive promoter. }\end{array}$} \\
\hline
\end{tabular}

a recombinant clone by complementation of a mutant host $(19,27,29,31,106)$.

\section{Multiple Cloning Sites}

It is usually desirable for a cloning vector to contain unique restriction sites for a variety of different restriction enzymes (31). Often, in E. coli vectors, these restriction sites are clustered and associated with the lac gene fragment that permits $\alpha$-complementation for $\beta$-galactosidase activity in a suitable ( $\Delta$ M15 lacZ deletion) E. coli host. This results in the well-known blue/white colony discrimination on X-gal IPTG plates. More recently, Pseudomonas strains, containing an E. coli DNA fragment carrying the $\Delta \mathrm{M} 15$ lac $Z$ deletion, have been constructed and permit visualization of the blue/white colony phenotype with vectors capable of $\alpha$-complementation (69).

\section{EXPRESSION VECTORS}

A number of different systems have been constructed to facilitate the artificial regulation and over-expression of a cloned gene (Table 2). The classical systems are based upon tried and tested regulator/promoter systems from $E$. coli, such as the $P_{l a c}$ or $P_{t a c}$ promoters and LacI repressor, inducible by IPTG promoters $(11,40)$; the thermo-sensitive lambda $\lambda c I_{857}$ repressor, with promoters $\lambda p_{R}$ and $\lambda p_{L}(30,80)$; and the arabinose repressor, $\mathrm{AraC}$, with the promoter $P_{B A D}$ induced by arabinose (94, 121). Recent improvements in RK2 vectors have led to new expression vectors based on the $P u / \mathrm{XylR}$ regulator (inducible by xylenes and toluene) and on the $P \mathrm{~m} / \mathrm{XylS}$ regulator (inducible by alkylbenzoates) $(15,16)$. The coliphage T7 $\phi 10$ promoter is also extremely efficient in a wide variety of bacteria when 
the T7 RNA polymerase is supplied in trans from a compatible plasmid $(27,28)$ or from a transposon integrated into the host chromosome $(32,34,58$, 133). Another advantage of the T7 promoter/polymerase system is that the proteins produced under its control continue to be synthesized in the presence of rifampicin, an inhibitor of the host RNA polymerase. Thus, recombinant proteins can be specifically labeled and visualized by SDS-PAGE (28).

A further development of the $\mathrm{T} 7$ promoter system placed the T7 polymerase gene under control of the $P m$ promoter, which is positively induced by XylS protein in the presence of alkylbenzoates. Both the $x y l S$ gene and the $P m$ T7 pol fusion were carried by a mini-Tn5 transposon that could be inserted into the chromosome of Pseudomonas putida. Target genes for the $\mathrm{T} 7$ polymerase were placed under the control of the $\mathrm{T} 7$ promoter and carried by multiple mini-transposons elsewhere on the P. putida chromosome. Thus, induction by alkyl-benzoate could provoke the simultaneous production of different target proteins in response to a single-inducer molecule in the environment (58). The $x y l S$ system permits excellent control of gene expression in many different bacteria and may have advantages over the $l a c$ and $\lambda$ systems, which are difficult to manipulate for environmental and large-scale purposes.

A useful tool for the purification of proteins overproduced in recombinant bacteria utilizes the $6 \times$ his-tagging system that permits proteins to be purified by metal affinity columns (14).

\section{TRANSPOSON TOOLS}

Transposons are mobile broad-hostrange genetic elements that can be transferred between bacteria by conjugation, transduction, and transformation. With the advent of genetic engineering, transposons have often been modified to construct special-purpose genetic tools (Table 3). The seminal work of Simon and co-workers (116) showed that a specially designed transposon delivery system could offer enormous advantages for transposon-mediated insertional mutagenesis. They constructed derivatives of narrow-host-

Table 3. Transposon Vectors

\begin{tabular}{|c|c|c|}
\hline Transposon & Properties & Reference \\
\hline Tn5-TC1 (series) & $\mathrm{Tc} R$ & (109) \\
\hline Tn5-B10 (series) & $\mathrm{Nm}^{\mathrm{R}}, \mathrm{mob}$ & $(116)$ \\
\hline Tn5-B60 & $\mathrm{Nm}^{\mathrm{R}}$, Ptac mobile promoter & $(116)$ \\
\hline Tn5-K28 (series) & $\mathrm{Tc}^{\mathrm{R}}, \mathrm{Sm} \mathrm{R}, \mathrm{mcs}$ & (67) \\
\hline Tn5-30Tp & $\mathrm{Km} R, \mathrm{Tp}^{\mathrm{R}}$ & (1) \\
\hline Tn5-Hy (series) & HyR & (12) \\
\hline $\begin{array}{l}\text { mini-Tn5-Cm } \\
\quad \text { (large series) }\end{array}$ & $\mathrm{Cm}$, tnp & $(34,35,59)$ \\
\hline $\begin{array}{r}\text { mini-Tn10-Km } \\
\text { (large series) }\end{array}$ & $\mathrm{Km} \mathrm{R}, t n p^{-}$ & $(34,35,59)$ \\
\hline mini-Tn5xylS/Pm::T7pol & $\begin{array}{l}\mathrm{Km} \mathrm{R}^{\mathrm{R}} \text {, tnp- } x y I S P m \text { promoter, } \\
\mathrm{T} 7 \mathrm{RNA} \text { polymerase }\end{array}$ & $(58)$ \\
\hline Tn1722-299Km & $\mathrm{Km} \mathrm{m}^{\mathrm{R}}, \mathrm{Tc}^{\mathrm{R}}, \mathrm{Cm} \mathrm{m}^{\mathrm{R}}$, oripACYC184 & $(127)$ \\
\hline $\begin{array}{l}\text { pTnMod-OCm } \\
\text { (large series) }\end{array}$ & $\mathrm{Cm}^{\mathrm{R}}$, tnp ${ }^{-}$, oripMB9 & (39) \\
\hline pTn5cat & $\begin{array}{l}\mathrm{Nm}^{\mathrm{R}} \text {, promoterless cat } R, \text { mob, } \\
\text { tnp-, oriColE1- }\end{array}$ & (83) \\
\hline Tn5-OT182 & $\begin{array}{l}\mathrm{Tc}^{\mathrm{R}}, \mathrm{Ap}^{\mathrm{R}} \text {, promoterless } \\
\text { lacZ, oriColE1 }\end{array}$ & (88) \\
\hline mini-OphoA & $\mathrm{Gm}^{\mathrm{R}}, p h o A$, oripMB1 & $(18,123)$ \\
\hline \multicolumn{3}{|c|}{$\begin{array}{l}\text { No attempt is made to list all transposons. When a series of similar variants is } \\
\text { available this is indicated by "series" in column } 1 . \text { Abbreviations are as in Tables } 1 \\
\text { and } 2 \text { except for tnp-, transposase negative transposon; oripACYC184, origin of } \\
\text { replication of plasmid pACYC184; oripMB9, origin of replication of plasmid pMB9; } \\
\text { oriColE1, origin of replication of plasmid ColE1. }\end{array}$} \\
\hline
\end{tabular}

range $E$. coli-specific plasmids $\mathrm{pA}$ CYC184 and pBR325 that contained the $m o b$ region of RK2 and could thus be transferred, by conjugation, to many different Gram-negative bacteria. The plasmids could not replicate in these foreign bacteria and thus acted as suicide plasmids. However, when the mob plasmids were also equipped with a transposon such as Tn5 or Tn10, the transposon could survive, at low frequency, by transposition to the host chromosome. An alternative transposon delivery technique relies on the narrow-host-range replicon of plasmid R6K, which can replicate when the replication protein $\pi$ is provided in trans but acts as a suicide plasmid when transferred to a strain lacking this protein (89). Irrespective of the delivery vehicle, the $E$. coli strain S17-1, containing an integrated conjugation proficient RP4 plasmid (116), is usually used. To permit the replication of the suicide R6K replicon, S17-1 is made lysogenic for $\lambda$ pir, which encodes the replication protein $\pi(73,89)$

The obvious utility of transposons prompted the construction of modified variants of $\mathrm{Tn} 5$, containing different combinations of antibiotic resistance genes $(1,12,109)$. Variants containing the RP4 mob region were also constructed (116). The Tn5 transposon was modified for use as a cloning vector by maximizing the number of restriction sites inside the Tn5 transposon and eliminating those within the carrier plasmid. Thus, foreign DNA could be cloned more easily into the transposon and was subsequently transposed, along with the transposon, into the chromosome of the recipient bacteria, following conjugation $(27,67)$. Bacteria carrying foreign DNA cloned within a transposon have the advantage of being stable in the absence of continued antibiotic selection. This is necessary for 
many types of environmental applications (e.g., bioremediation or biocontrol, by the species of Pseudomonas, Sphingomonas, Ralstonia, Comamonas, and Burkholderia or nitrogen fixation, by the species of Rhizobium, Azorhizobium, and Bradyrhizobium).

A large series of mini-transposon vectors was designed in which Tn5 transposons were reduced to a minimum size; they essentially consisted of only the two IS50 terminal sequences and a selective marker (Table 3 ). Another useful characteristic of this minitransposon series is the presence in each transposon of unique sites for rare-cutting restriction enzymes, Not $\mathrm{I}$ and SfiI, into which foreign DNA may be cloned $(35,36,59)$. The transposase gene was located on the suicide plasmid adjacent to, but outside of, the mini-transposon so that transposition results in the dissociation of the transposon from its transposase gene. This further enhances genetic stability, prevents secondary transposition, and thus limits horizontal transfer. $(35,36,59)$.

A unique kind of transposon was based on the narrow-host-range $E$. coli pMB8 replicon. By the insertion of a second 38-bp Tn3 inverted repeat, pMB8-based vectors were converted into transposons that could form co-integrates with any broad-host-range plasmid and then be transferred to alternate hosts by conjugation (72).

Various modified transposons contain an origin of replication that is functional in certain hosts but not others. Thus, they are plasmids in the permissive host but can exist only as integrated transposons in the non-permissive host. These are generally referred to as selfcloning vectors or plasposons because they form plasmids when they are excised from the non-permissive host, are re-ligated, and transformed into the permissive host. One series of modular mini-transposons (Table 3, pTnMod) is based on the RK6 origin of replication (39). Thus, an RK6-based pTnmod plasposon inserted into, for example, the $B$. cepacia genome may be excised with an appropriate restriction enzyme, circularized using DNA ligase, and then transformed into the permissive host $E$. coli ( $\lambda$ pir). Using these self-cloning vectors, the gene into which the plasposon is inserted may be cloned and sequenced in as few as two days. Since plasposons carry sites for rare-cutting restriction enzymes, they also have potential applications for the physical mapping of unknown genomes and the preparation of large restriction fragments.

A similar Tn5-based plasmid/transposon, pTn5cat, carrying the origin of replication of ColE1, the mob region of $\mathrm{RP} 4$, and sites for the rare-cutting restriction enzymes $(83,88)$ has also been described. Another self-cloning vector is based on a transposon Tn1722, variant Tn1722-299Km, which carries the E. coli-specific plasmid pACYC184 (1). More recently, a self-cloning system coupled to a phoA promoter-probe vector (123) to facilitate cloning of secreted proteins was constructed (18).

With the increased availability of completely sequenced bacterial genomes, new methods are necessary for the mass identification of essential genes. A new technique (136) exploits the highly efficient in vivo transposition of the newly developed mariner transposon. With this system, one transposition event can be obtained per 200 recipients in $P$. aeruginosa, and the genetic locations of the insertion sites can be massscreened by gel electrophoresis, follow ing PCR. The absence of a transposon insertion in a particular gene (defined by the genomic sequence) provides good evidence that the gene is essential for growth under the conditions selected. This presumptive result is then confirmed by an efficient site-specific recombination method of gene replacement (see section on gene replacement).

\section{INDICATOR GENES AND PROMOTER-PROBE VECTORS}

For a great many years, indicator genes have proved invaluable for the genetics of E. coli. There are two principal reasons for using indicator genes. First, promoterless indicator genes are useful for studying the control of gene activity (the promoter-probe vectors discussed in this section). Second, indicator genes serve to genetically mark a particular bacterium so that it can be uniquely identified, selected, and quantified at a later time.

Transcriptional fusions of indicator genes provide information on the genet- ic control of the gene to which they are fused. Similarly, translational fusions provide information on posttranslational processing, protein secretion, and localization in the cell. In many cases, a promoter-probe plasmid contains multiple cloning sites upstream of a promoterless indicator gene so that cloning of specific or random fragments carrying promoter activity will result in gene expression under appropriate conditions in the relevant host $(105,106)$. In other cases, homologous recombination with the chromosomal gene, rather than cloning, is used to accomplish the fusion event (65). In still other cases, the promoter-probe plasmid may be a minitransposon that randomly inserts into the host chromosome and frequently causes fusions with an active promoter (34). The latter two systems have the advantage that the gene fusion is similar to a single copy in its normal chromosomal location, thereby avoiding potential problems caused by position or plasmid copy number. Transposon Tn5 has been the most popular transposon used in promoter-probe constructions, but others include Tn3 (85). The transposon IS903 $\phi k a n$ (124) is also worthy of special mention because not only is its transposase located outside of the transposon but also it is under the control of the lac promoter. This means that transposition can be induced by IPTG and detected by the resistance to kanamycin. IS903 $\phi \mathrm{kan}$ is therefore a useful tool for bacteria that are poor recipients for transformation or conjugation.

The classical reporter gene that was first used in E. coli genetics is lacZ, which codes for $\beta$-galactosidase. Promoter-probe vectors carrying lac $Z$ have been successfully applied to Pseudomonas, Rhizobium and other Gramnegative bacteria $(33,64,65,71,78,88$, 116). The much smaller lacZ $\alpha$ fragment has also been used (105), although this system requires specially designed bacteria that carry a DNA fragment of $E$. coli, which contains the complementing $\triangle \mathrm{M} 15$ lac $Z$ deletion (69). Many other promoterless indicator genes have been used in promoterprobe plasmid vectors, including antibiotic resistance genes for streptomycin (11), tetracycline (48), chloramphenicol $(47,83,96)$, kanamycin (124), gentamycin (116), and ampicillin (64). 
Other promoterless indicator genes include: $x y l E$, catechol 2,3-dioxygenase from $P$. putida $(64,67,74)$; galK, galactokinase from $E$. coli (30); inaZ, ice nucleation activity (81); luxAB or luxE$C A B D$, luciferase from Vibrio fischerei $(35,48,66,134)$; luc, luciferase from fireflies (97); $g f p$ from Aequorea victoria $(52,85,96,120)$; gusA, $\beta$-glucuronidase of E. coli (103); celB, thermostable $\beta$-glucosidase of Pyrococcus furiosus (114); and phoA, alkaline phosphatase from E. coli $(18,48,64$, 123). Each of these systems offers some advantages, such as selection, ease of enzyme quantification, color reaction, light emission or fluorescence. The alkaline phosphatase protein-fusion transposon has the advantage that the enzyme is active only after export from the cytoplasm, which allows for the enrichment of insertions into genes that encode secreted proteins $(18,123)$. Recently, GFP has replaced many other indicator systems because of the many advantages it offers.

\section{IN VIVO EXPRESSION TECHNOLOGY}

There is enormous interest in know ing which genes are specifically expressed by bacterial pathogens during pathogenesis. Building on the observation that these genes are quite different from those expressed by the same pathogen during growth in the laboratory, two new and related methods, in vivo expression technology (IVET) and recombinase-based in vivo expression technology (RIVET), have been devised to identify genes that are expressed in the host during pathogenesis. These important innovations have been the subject of extensive reviews $(20,21,56,82,118)$ and will be dealt with only briefly here. Both are based on promoter-probe plasmids that permit the identification of promoters that are active during pathogenesis. In IVET and RIVET vectors, potential promoter-containing DNA fragments from pathogenic microorganisms are cloned in front of a promoterless reporter gene and its in vivo expression profile is then monitored.

In the case of IVET, the reporter gene is essential for pathogenic growth in the host. Such genes include metabolic genes, such as purA or thyA, respectively, which are necessary for purine and thymine biosynthesis (118, 119 ), and $a s d$, which is necessary for diaminopimelate biosynthesis (52). The recipient host carries a deletion for the corresponding gene to permit genetic complementation. Antibiotic resistance genes, such as cat, chloramphenicol resistance (82), and tmp, trimethoprim resistance (115), where the host is treated with the appropriate antibiotic, have also been used.

In addition to these selective genes, the expression of visible indicator genes may be simultaneously monitored (52). GFP may be particularly interesting for noninvasive real-time monitoring. A technique known as differential fluorescence induction uses a promoter-trap strategy involving GFP coupled with semiautomated fluorescence-activated cell sorting to directly isolate in vivo pathogens that express the indicator gene $(128,129)$.

For both IVET and RIVET, the promoterless reporter genes carried by an ori-RK6 suicide plasmid are fused to the pool of promoter fragments from the pathogenic bacterium in vitro before transformation of $E$. coli-( $\lambda$ pir $)$. It is necessary to use a fusion library large enough so that there would be a $99 \%$ probability of fusion for every gene in the bacterium. The transformation pool is then conjugated to the recipient pathogen. In the pathogen, the transferred ori-R6K plasmid does not replicate, and integration must thus take place by Campbell-type homologous recombination between the promoter-containing fragment and the corresponding region of the host chromosome. This Campbell-type insertion is additive so that the host gene is neither inactivated nor deregulated in the process.

The RIVET technology uses as different kind of promoterless reporter gene compared to IVET. Instead of a gene essential to the host survival, RIV ET uses a promoterless site-specific recombinase gene [e.g., the E. coli $\operatorname{Tn} \gamma \delta$ resolvase (21) or the cre recombinase of phage P1 (6), whose expression is of no consequence to the survival of the pathogen]. The expression of the sitespecific recombinase is monitored by its ability to excise indicator genes 
(e.g., $\mathrm{Km}^{\mathrm{R}}$, kanamycin resistance, and $s a c B$, sucrose sensitivity) located between site-specific recombination sites (res sites for $\gamma \delta$ resolvase and lox sites for cre recombinase) artificially inserted elsewhere on the bacterial chromosome. This has the advantage that RIV ET can be used to identify genes that are temporally expressed during pathogenesis or that are tissue-specific.

In both IVET and RIVET, the authenticity of the putative pathogen genes expressed in vivo are subsequently verified by more classical techniques such as DNA sequencing, amino acid sequence comparisons, and mutation and deletion analysis.

\section{ENVIRONMENTAL MARKER GENES}

Recent years have seen an increased interest in the role of microorganisms in the environment. To experimentally investigate microbial interactions in a natural ecosystem, it is often necessary to introduce specific bacteria into the environment or into an artificial microcosm. For this purpose, the bacteria must be genetically marked so that they can be detected and quantified during the experiment $(62,99)$. Often, this genetic marking is performed by the insertion of mini-transposons (33), although, occasionally, stable plasmids are used (12). Numerous strategies have been devised to genetically mark these transposons. Usually, these include a combination of selectable markers to facilitate the recovery of the bacteria on Petri dishes. The selectable marker is often an antibiotic resistance gene (12), but for environmentally friendly reasons, other selective markers have been used (e.g., resistance to the herbicide Bialaphos, to mercuric salts and organomercuric compounds, and to arsenite) (59). Some of these non-antibiotic markers are not entirely satisfactory because of problems of spontaneous mutation or high tolerance (108). More recently, new mini-transposons and plasmids have been constructed that use tellurite resistance (108) and nickel resistance (122). Both of these systems give excellent selection with low background. In Pseudomonas, bacteria carrying specific siderophore receptors can be specifically isolated from environmental samples using iron-deprived medium supplemented with the appropriate siderophore (100). Still other selective systems may be based on catabolic genes. For Pseudomonads, which lack the ability to use lactose as a carbon source, the entire lac operon, carried by a plasmid (72) or a mini-transposon (53), has been used as a selective marker. Similarly, in certain Pseudomonads, the upper TOL operon, carried by a transposon or a plasmid, may be used as a selective marker. Toluene is converted to benzoate that can then be metabolized to Krebs cycle intermediates by the chromosomal ortho-cleavage pathway $(98,108)$.

Genetic marking usually includes genes for visual screening by an enzymatic color reaction, visible light production, or fluorescence. The most popular visual marker genes are $l a c Z$, $\beta$-galactosidase (44); gusA, $\beta$-glucosidase (114); lux, bacterial luciferase (131); luc, insect luciferase (22); $x y l E$, catechol 2-3 dioxygenase (107); GFP $(45,85)$; and ice, ice nucleation protein (81). Among these, GFP $(45,46)$ is the most recent and the most popular, since it has numerous advantages over other systems. It is easily and non-destructively detected by illumination with blue or near-UV light and, unlike all other systems, requires no substrate. Individual colonies can be detected with a hand-held, long-wave UV lamp. Initially, the detection of single bacterial cells expressing GFP using epifluorescent microscopy was difficult, but several groups $(38,55)$ have isolated mutants of the $g f p$ gene with up to $40 \times$ enhanced fluorescence. Red-, blue-, and yellowgreen-shifted mutants are available and, with suitable filters, can be detected simultaneously in the same sample. GFP has the advantage of being stable to temperature, $\mathrm{pH}$, and denaturing agents. It can thus be detected in dead cells-even those fixed with paraformadehyde for microscopic observation. For some types of experiments involving real-time changes, this extreme stability can be a disadvantage. To solve this problem, unstable variants of GFP have been constructed that have reduced half-lives compared with the wild-type protein (7). The multitude of possible applications of GFP $(26,45)$ cannot be summarized here but includes the visualization of the process of infection-thread formation in $R$. meliloti (51), detection of Pseudomonads on plant roots (17), monitoring the survival of bioremediation bacteria in polluted soils (46), and conjugation on leaf surfaces (95), in biofilms (23), and in marine bacterial communities (25).

The luciferase genes (lux of $V$. fischeri and luc of firefly and click beetle) have also been popular for environmental monitoring (99). Both types of luciferase need a substrate, luciferin (a hetercyclic carboxylic acid) for $l u c$ and long-chain aldehyde for $\operatorname{lu} x A B$. The remaining lux genes (luxCDE) are concerned with substrate synthesis and, when present, permit light production in the absence of an exogeneously supplied aldehyde substrate. Under favorable conditions, bioluminescent bacterial colonies can be detected by eye in a dark room. More sensitive methods include X-ray films and photography, while the most sensitive methods involve the use of a scintillation counter, a luminometer, or charge-coupled-device-enhanced microscopy. No attempt can be made here to enumerate all of the applications of $l u x$-marked bacteria, but some examples are illustrative. Light emission by single bacterial cells was monitored on plant leaves (132) or roots (102). Recombinant Pseudomonads carrying the luxCDABE genes to the $n a h G$ promoter were able to produce light when the pollutant naphthalene was present in the medium. This system used fiber optics for the online monitoring of the presence of napthalene $(57,104)$. Similar systems for the detection of biphenyl and benzene, toluene, ethylbenzene, and xylene were also constructed by fusion to the biphenyl promoter of $R$. eutropha (79) or to the tod promoter of $P$. putida F1, respectively (8). Lux fusions able to detect the presence of a variety of heavy metals $\left(\mathrm{Ni}^{2+}, \mathrm{Cu}^{2+}, \mathrm{Hg}^{2+}, \mathrm{Cr}^{6+/ 3+}\right.$, and $\mathrm{Pb}^{2+}$ ) have also been constructed $(24,125,131)$.

\section{CONDITIONAL LETHALITY AND SUICIDE SYSTEMS}

There are a number of systems that 
permit the conditional killing of host bacteria by means of the controlled expression of lethal genes. These systems have two main applications. First, they may be used in the laboratory to eliminate particular bacteria, genetic regions, or plasmids during various forms of gene replacement. Second, they serve to eliminate bacteria in particular environmental situations. Thus, in the case of a bacterium designed for de-pollution, it may be desirable that the bacterium survives only as long as the environment is contaminated by that particular pollutant. Following the complete degradation of the pollutant, the bacterium is programmed to self-destruct. An alternative scenario aims at preventing horizontal transfer to other environmental bacteria. Correctly designed suicide systems may accomplish both of these purposes (90). One such system depends on the gef gene of $E$. coli, which, when it is expressed, kills many different types of bacteria by generating pores in the cell membrane, thereby destroying the membrane potential. To carefully control gef expression, a genetic relay was constructed and inserted into a mini-transposon vector. In this system, the lacI repressor gene was fused to the $P m$ promoter of $P$. putida, which is controlled by the positive regulator $x y l S$ that is responsive to 3methyl-benzoate. Thus, the LacI repressor was synthesized in the presence of 3-methyl-benzoate but not in its absence. The same transposon carried the gef gene fused to the lac promoter. Thus, the deprivation of 3-methyl-benzoate resulted in derepression of the $l a c$ promoter and the synthesis of the lethal gef gene product. The system provides a model for the suicide of a pollution bioremediation bacterium, following the elimination of the pollutant, and was shown to work well in the laboratory and in outdoor soil tests $(63,91)$.

A different conditional lethality system was based on the colicin E3 gene (colE3), which, when it is expressed, is able kill a variety of hosts by cleavage of the $16 \mathrm{~S}$ ribosomal RNA. In a natural situation, this lethality function is counteracted by an immunity function (immE3). To examine whether the killing function could be used to prevent the horizontal transfer of plasmid DNA to other bacteria, the colE3 gene was placed on a plasmid and the immE3 was placed on the chromosome of $E$. coli or $P$. putida. Thus, in the case of the horizontal transfer of the plasmid to another bacterium, the colE3 gene would be transferred in the absence of the $i m m E 3$ gene, resulting in cell death. This system was able to prevent horizontal transfer to a wide variety of Gram-negative bacteria $(42,93,101)$. 


\section{GENE REPLACEMENT, DELETION, AND INSERTION}

The complete sequencing of several Gram-negative genomes has revealed large numbers of fun (function unknown) genes. The function of these genes might be revealed by their deletion from the chromosome or their replacement by indicator genes to investigate the resulting phenotypic changes. The techniques for allele replacement and gene deletion/knockout (126) all involve the transfer of the cloned gene [(modified by mutation, deletion, or insertion of antibiotic resistance genes, often in the form of $\Omega$-interposons $(2,3,49)]$ to the recipient bacterium on a non-replicating and/or suicide plasmid. The circular plasmid then integrates by Campbell-type homologous recombination. Excision from this merodiploid can occur by spontaneous reversal of the recombination event and, in a proportion of cases, leads to the replacement of the wild-type allele by the mutant allele (126). In some cases, the excision event can be selected by the use of a suicide function [e.g., the $s a c B$ gene, conferring sensitivity to sucrose $(68,112,113)$ or the rpsL gene, conferring dominant streptomycin sensitivity (117)] in the original vector.

A number of different systems have used site-specific recombination to cause in vivo deletion of specific regions of the bacterial chromosome or complex plasmids. Such systems may be useful for precise genetic analysis. They are also particularly useful for the removal of antibiotic genes and other DNA sequences involved in recombinant DNA constructions so that the final strain differs from the parent only in containing the desired genes of interest. A specific deletion in the $\operatorname{trf} A$ gene of plasmid RK2 was generated by introducing phage P1 loxP sites on either side of the gene. The transfer to a strain expressing the P1 cre recombinase resulted in the specific deletion of the target gene (9). The multimer resolution system for plasmid partition ( $m r s$ ) on plasmid RP4 was used to generate sitespecific deletions in transposons on the Pseudomonas chromosome (77). The mrs site-specific recombinase acts at two res (resolution) sites to excise DNA located between them. In a simi- lar situation, the mrs was used to specifically delete the antibiotic resistance genes from a transposon, follow ing transposition to the chromosome. The result was a quasi-natural strain that differed from the original parent only in having the upper operon of the TOL plasmid pWWO (98).

A system of site-specific plasmid integration of a non-replicating plasmid mini-CTX was devised using the $\phi C T X$ phage integrase in combination with the appropriate attachment sites. The Flp/ FRT site-specific recombination of yeast was then used to remove undesired plasmid DNA sequences $(13,60,61)$. Under optimized conditions, these sitespecific recombination techniques could be used to create recombinant bacteria that contain only the heterologous gene of interest and are free of plasmid sequences. Such bacteria are desirable for several purposes, including environmental release and live oral vaccines.

Recently, a highly efficient system of site-specific recombination-aided gene replacement was reported by Wong et al. (136). The recipient host bacterium, $P$. aeruginosa, was manipulated to express the I-SceI endonuclease, while the conjugally transferred suicide plasmid contained the replacement gene between two I-SceI clevage sites. The presence of the I-SceI endonuclease is thought to cleave the incoming plasmid, thus preventing co-integrate formation and possibly stimulating homologous recombination. The method was highly efficient, giving $100 \%$ gene replacement.

\section{CONCLUSION}

Over the past 10 years, the level of sophistication of recombinant DNA techniques applicable to Gram-negative bacteria has increased to rival those of E. coli. The availability of completed bacterial genomic sequences for many Gram-negative bacteria means that efficient high-throughput techniques will increasingly be needed for functional genomic analysis of these extraordinarily diverse bacteria.

\section{REFERENCES}

1.Abe, M., M. Tsuda, M. Kimoto, S. Inouye, A. Nakazawa, and T. Nakazawa. 1996. A genetic analysis system of Burkholderia cepacia: construction of mobilizable transposons and a cloning vector. Gene 174:191-194.

2.Alexeyev, M.F. 1995. Three kanamycin resistance gene cassettes with different polylinkers. BioTechniques 18:52-56.

3.Alexeyev, M.F. 1999. The pKNOCK series of broad-host-range mobilizable suicide vectors for gene knockout and targeted DNA insertion into the chromosome of gram-negative bacteria. BioTechniques 26:824-828.

4.Alexeyev, M.F. and I.N. Shokolenko. 1995. Mini-Tn10 transposon derivatives for insertion mutagenesis and gene delivery into the chromosome of gram-negative bacteria. Gene 160:59-62.

5.Alexeyev, M.F., I.N. Shokolenko, and T.P. Croughan. 1995. Improved antibiotic-resistance gene cassettes and omega elements for Escherichia coli vector construction and in vitro deletion/insertion mutagenesis. Gene 160:63-67.

6.Altier, C. and M. Suyemoto. 1999. A recom binase-based selection of differentially expressed bacterial genes. Gene 240:99-106.

7.Andersen, J.B., C. Sternberg, L.K. Poulsen, S.P. Bjorn, M. Givskov, and S. Molin. 1998. New unstable variants of green fluorescent protein for studies of transient gene expression in bacteria. Appl. Environ. Microbiol. 64:2240-2246.

8.Applegate, B.M., S.R. Kehrmeyer, and G.S. Sayler. 1998. A chromosomally based todluxCDABE whole-cell reporter for benzene, toluene, ethybenzene, and xylene (BTEX) sensing. Appl. Environ. Microbiol. 64:27302735.

9.Ayres, E.K., V.J. Thomson, G. Merino, D. Balderes, and D.H. Figurski. 1993. Precise deletions in large bacterial genomes by vectormediated excision (VEX). The trfA gene of promiscuous plasmid RK2 is essential for replication in several gram-negative hosts. J. Mol. Biol. 230:174-185.

10.Bagdasarian, M.M. and K.N. Timmis. 1982. Host: vector systems for gene cloning in Pseudomonas. Curr. Top. Microbiol. Im munol. 96:47-67.

11.Bagdasarian, M.M., E. Amann, R. Lurz, B. Ruckert, and M. Bagdasarian. 1983. Activity of the hybrid trp-lac (tac) promoter of Escherichia coli in Pseudomonas putida. Construction of broad-host-range, controlledexpression vectors. Gene 26:273-282.

12.Barnett, M.J., V. Oke, and S.R. Long. 2000. New genetic tools for use in the Rhizobiaceae and other bacteria. BioTechniques 29:240245.

13. Becher, A. and H.P. Schweizer. 2000. Integration-proficient Pseudomonas aeruginosa vectors for isolation of single-copy chromosomal lacZ and lux gene fusions. BioTechniques 29:948-952.

14.Bertani, I., G. Devescovi, and V. Venturi. 1999. Controlled specific expression and purification of $6 \times$ His-tagged proteins in Pseudomonas. FEMS Microbiol. Lett. 179:101-106.

15.Blatny, J.M., T. Brautaset, H.C. WintherLarsen, K. Haugan, and S. Valla. 1997. Construction and use of a versatile set of broad-host-range cloning and expression vectors based on the RK2 replicon. Appl. Envi- 
ron. Microbiol. 63:370-379.

16.Blatny, J.M., T. Brautaset, H.C. WintherLarsen, P. Karunakaran, and S. Valla. 1997. Improved broad-host-range RK2 vectors useful for high and low regulated gene expression levels in gram-negative bacteria. Plasmid 38:35-51

17.Bloemberg, G.V., G.A. O'Toole, B.J Lugtenberg, and R. Kolter. 1997. Green fluorescent protein as a marker for Pseudomonas spp. Appl. Environ. Microbiol. 63:4543-4551.

18.Bolton, A.J. and D.E. Woods. 2000. Selfcloning minitransposon phoA gene-fusion system promotes the rapid genetic analysis of secreted proteins in gram-negative bacteria. BioTechniques 29:470-474

19.Brunel, F. and J. Davison. 1988. Cloning and sequencing of Pseudomonas genes encoding vanillate demethylase. J. Bacteriol. 170:4924 4930.

20.Camilli, A., D.T. Beattie, and J.J. Mekalanos. 1994. Use of genetic recombination as a reporter of gene expression. Proc. Natl. Acad. Sci. USA 91:2634-2638.

21.Camilli, A. and J.J. Mekalanos. 1995. Use of recombinase gene fusions to identify Vibrio cholerae genes induced during infection. Mol. Microbiol. 18:671-683.

22.Cebolla, A., M.E. Vazquez, and A.J. Palomares. 1995. Expression vectors for the use of eukaryotic luciferases as bacterial markers with different colors of luminescence. Appl. Environ. Microbiol. 61:660-668

23.Christensen, B.B., C. Sternberg, J.B. Andersen, and O.S. Molin. 1998. In situ detection of gene transfer in a model biofilm engaged in degradation of benzyl alcohol APMIS Suppl. 84:25-28.

24.Corbisier, P. 1997. Bacterial metal-lux biosensors for a rapid determination of the heavy metal bioavailability and toxicity in solid samples. Res. Microbiol. 148:534-536.

25.Dahlberg, C., M. Bergstrom, and M. Hermansson. 1998. In situ detection of high levels of horizontal plasmid transfer in marine bacterial communities. Appl. Environ. Microbiol. 64:2670-2675.

26.Davison, J. 1999. Genetic exchange between bacteria in the environment. Plasmid 42:73 91

27.Davison, J., F. Brunel, K. Kone, and N. Chevalier. 1990. Recombinant DNA vectors for pseudomonas, p. 242-251. In S. Silver, A.M. Chakrabarty, B. Iglewski, and S. Kaplan (Eds.), Pseudomonas, Biotransformations, Pathogenesis, and Evolving Biotechnology. American Society for Microbiology, Washington, DC.

28.Davison, J., N. Chevalier, and F. Brunel. 1989. Bacteriophage T7 RNA polymerasecontrolled specific gene expression in Pseudomonas. Gene 83:371-375

29.Davison, J., M. Heusterspreute, and F. Brunel. 1987. Restriction site bank vectors for cloning in gram-negative bacteria and yeast. Methods Enzymol. 153:34-54.

30.Davison, J., M. Heusterspreute, N. Chevalier, and F. Brunel. 1987. A "phase-shift" fusion system for the regulation of foreign gene expression by $\lambda$ repressor in gram-negative bacteria. Gene 60:227-235.

31.Davison, J., M. Heusterspreute, N. Cheva- lier, V. Ha-Thi, and F. Brunel. 1987. Vectors with restriction site banks. V. pJRD215, a wide-host-range cosmid vector with multiple cloning sites. Gene 51:275-280.

32.de Lorenzo, V. 1992. Genetic engineering strategies for environmental applications. Curr. Opin. Biotechnol. 3:227-231

33.de Lorenzo, V. 1994. Designing microbial systems for gene expression in the field. Trends Biotechnol. 12:365-371.

34.de Lorenzo, V. and K.N. Timmis. 1994 Analysis and construction of stable phenotypes in gram-negative bacteria with Tn5- and Tn10-derived minitransposons. Methods Enzymol. 235:386-405.

35.de Lorenzo, V., M. Herrero, U. Jakubzik, and K.N. Timmis. 1990. Mini-Tn5 transposon derivatives for insertion mutagenesis, promoter probing, and chromosomal insertion of cloned DNA in gram-negative eubacteria. J. Bacteriol. 172:6568-6572.

36.de Lorenzo, V., M. Herrero, J.M. Sanchez, and K.N. Timmis. 1998. Mini-transposons in microbial ecology and environmental biotechnology. FEMS Microbiol. Ecol. 27:211-224.

37.DeFeyter, R., C.I. Kado, and D.W. Gabriel. 1990. Small, stable shuttle vectors for use in Xanthomonas. Gene 88:65-72.

38.Delagrave, S., R.E. Hawtin, C.M. Silva, M.M Yang, and D.C. Youvan. 1995. Red-shifted excitation mutants of the green fluorescent protein. Biotechnology (NY) 13:151-154.

39.Dennis, J.J. and G.J. Zylstra. 1998. Plasposons: modular self-cloning minitransposon derivatives for rapid genetic analysis of gramnegative bacterial genomes. Appl. Environ. Microbiol. 64:2710-2715.

40.Deretic, V., S. Chandrasekharappa, J.F. Gill, D.K. Chatterjee, and A.M. Chakrabarty. 1987. A set of cassettes and improved vectors for genetic and biochemical characterization of Pseudomonas genes. Gene 57:6172

41.DeShazer, D. and D.E. Woods. 1996. Broadhost-range cloning and cassette vectors based on the R388 trimethoprim resistance gene. BioTechniques 20:762-764.

42.Diaz, E., M. Munthali, V. de Lorenzo, and K.N. Timmis. 1994. Universal barrier to lateral spread of specific genes among microorganisms. Mol. Microbiol. 13:855-861.

43.Ditta, G., T. Schmidhauser, E. Yakobson, P. Lu, X.W. Liang, D.R. Finlay, D. Guiney, and D.R. Helinski. 1985. Plasmids related to the broad host range vector, pRK290, useful for gene cloning and for monitoring gene expression. Plasmid 13:149-153.

44.Drahos, D., B.C. Hemming, and S. McPherson. 1986. Tracking recombinant organisms in the environment: $\beta$-galactosidase as a selectable non-antibiotic marker for fluorescent pseudomonads. Biotechnology (NY) 4:439. 444.

45.Errampalli, D., K. Leung, M.B. Cassidy, M. Kostrzynska, M. Blears, H. Lee, and J.T. Trevors. 1999. Applications of the green fluorescent protein as a molecular marker in environmental microorganisms. J. Microbiol. Methods 35:187-199.

46.Errampalli, D., O. Tresse, H. Lee, and J.T. Trevors. 1999. Bacterial survival and mineralization of p-nitrophenol in soil by green fluo- rescent protein-marked Moraxella sp. G21 encapsulated cells. FEMS Microbiol. Ecol. 30:229-236.

47.Farinha, M.A. and A.M. Kropinski. 1989 Construction of broad-host-range vectors for general cloning and promoter selection in Pseudomonas and Escherichia coli. Gene 77:205-210.

48.Farinha, M.A. and A.M. Kropinski. 1990 Construction of broad-host-range plasmid vectors for easy visible selection and analysis of promoters. J. Bacteriol. 172:3496-3499.

49.Fellay, R., H.M. Krisch, P. Prentki, and J. Frey. 1989. Omegon-Km: a transposable element designed for in vivo insertional mutagenesis and cloning of genes in gram-negative bacteria. Gene 76:215-226.

50.Frey, J. and H.M. Krisch. 1985. Omega mutagenesis in gram-negative bacteria: a selectable interposon which is strongly polar in a wide range of bacterial species. Gene 36:143150.

51.Gage, D.J., T. Bobo, and S.R. Long. 1996. Use of green fluorescent protein to visualize the early events of symbiosis between Rhizobium meliloti and alfalfa (Medicago sativa). J. Bacteriol. 178:7159-7166.

52.Handfield, M., H.P. Schweizer, M.J. Mahan, F. Sanschagrin, T. Hoang, and R.C. Levesque. 1998. ASD-GFP vectors for in vivo expression technology in Pseudomonas aeruginosa and other gram-negative bacteria. BioTechniques 24:261-264.

53.Hansen, L.H., S.J. Sorensen, and L.B. Jensen. 1997. Chromosomal insertion of the entire Escherichia coli lactose operon, into two strains of Pseudomonas, using a modified mini-Tn5 delivery system. Gene 186:167-173.

54.Heeb, S., Y. Itoh, T. Nishijyo, U. Schnider, C. Keel, J. Wade, U. Walsh, F. O'Gara et al. 2000. Small, stable shuttle vectors based on the minimal pVS1 replicon for use in gramnegative, plant-associated bacteria. Mol. Plant Microbe Interact. 13:232-237.

55.Heim, R. and R.Y. Tsien. 1996. Engineering green fluorescent protein for improved brightness, longer wavelengths and fluorescence resonance energy transfer. Curr. Biol. 6:178182.

56.Heithoff, D.M., C.P. Conner, P.C. Hanna, S.M. Julio, U. Hentschel, and M.J. Mahan. 1997. Bacterial infection as assessed by in vivo gene expression. Proc. Natl. Acad. Sci. USA 94:934-939.

57.Heitzer, A., K. Malachowsky, J.E. Thonnard, P.R. Bienkowski, D.C. White, and G.S. Sayler. 1994. Optical biosensor for environmental on-line monitoring of naphthalene and salicylate bioavailability with an immobilized bioluminescent catabolic reporter bacterium. Appl. Environ. Microbiol. 60:14871494

58.Herrero, M., V. de Lorenzo, B. Ensley, and K.N. Timmis. 1993. A T7 RNA polymerasebased system for the construction of Pseudomonas strains with phenotypes dependent on TOL-meta pathway effectors. Gene 134:103106.

59.Herrero, M., V. de Lorenzo, and K.N. Tim mis. 1990. Transposon vectors containing non-antibiotic resistance selection markers for cloning and stable chromosomal insertion of 
foreign genes in gram-negative bacteria. $\mathrm{J}$ Bacteriol. 172:6557-6567.

60.Hoang, T.T., R.R. Karkhoff-Schweizer, A.J. Kutchma, and H.P. Schweizer. 1998. A broad-host-range Flp-FRT recombination system for site-specific excision of chromosomally located DNA sequences: application for isolation of unmarked Pseudomonas aeruginosa mutants. Gene 212:77-86.

61.Hoang, T.T., A.J. Kutchma, A. Becher, and H.P. Schweizer. 2000. Integration-proficient plasmids for Pseudomonas aeruginosa: sitespecific integration and use for engineering of reporter and expression strains. Plasmid 43:59-72.

62.Jansson, J.K. and J.I. Prosser. 1997. Quantification of the presence and activity of specific microorganisms in nature. Mol. Biotechnol. 7:103-120.

63.Jensen, R.B. and K. Gerdes. 1995. Programmed cell death in bacteria: proteic plasmid stabilization systems. Mol. Microbiol. 17:205-210.

64.Kahrs, A.F., S. Odenbreit, W. Schmitt, D. Heuermann, T.F. Meyer, and R. Haas. 1995. An improved TnMax mini-transposon system suitable for sequencing, shuttle mutagenesis and gene fusions. Gene 167:53-57.

65.Kalogeraki, V.S. and S.C. Winans. 1997. Suicide plasmids containing promoterless reporter genes can simultaneously disrupt and create fusions to target genes of diverse bacteria. Gene 188:69-75.

66. Kamoun, S. and C.I. Kado. 1990. A plantinducible gene of Xanthomonas campestris pv. campestris encodes an exocellular component required for growth in the host and hypersensitivity on nonhosts. J. Bacteriol. 172:5165-5172.

67.Kaniga, K. and J. Davison. 1991. Transposon vectors for stable chromosomal integration of cloned genes in rhizosphere bacteria. Gene 100:201-205.

68.Kaniga, K., I. Delor, and G.R. Cornelis. 1991. A wide-host-range suicide vector for improving reverse genetics in gram- negative bacteria: inactivation of the blaA gene of Yersinia enterocolitica. Gene 109:137-141.

69. Karkhoff-Schweizer, R.R. and H.P. Schweizer. 1994. Utilization of a mini-Dlac transposable element to create an $\alpha$-complementation and regulated expression system for cloning in Pseudomonas aeruginosa. Gene 140:7-15.

70.Keen, N.T., S. Tamaki, D. Kobayashi, and D. Trollinger. 1988. Improved broad-hostrange plasmids for DNA cloning in gram-negative bacteria. Gene 70:191-197.

71.Kessler, B., V. de Lorenzo, and K.N. Tim mis. 1992. A general system to integrate lacZ fusions into the chromosomes of gram-negative eubacteria: regulation of the Pm promoter of the TOL plasmid studied with all controlling elements in monocopy. Mol. Gen. Genet. 233:293-301.

72.Kok, M., M. Rekik, B. Witholt, and S. Harayama. 1994. Conversion of pBR322based plasmids into broad-host-range vectors by using the Tn 3 transposition mechanism. J. Bacteriol. 176:6566-6571.

73.Kolter, R., M. Inuzuka, and D.R. Helinski. 1978. Trans-complementation-dependent re- plication of a low molecular weight origin fragment from plasmid R6K. Cell 15:11991208.

74.Konyecsni, W.M. and V. Deretic. 1988 Broad-host-range plasmid and M13 bacteriophage-derived vectors for promoter analysis in Escherichia coli and Pseudomonas aeruginosa. Gene 74:375-386.

75.Kovach, M.E., P.H. Elzer, D.S. Hill, G.T. Robertson, M.A. Farris, R.M. Roop, and K.M. Peterson. 1995. Four new derivatives of the broad-host-range cloning vector pBBR1MCS, carrying different antibiotic-resistance cassettes. Gene 166:175-176.

76.Kovach, M.E., R.W. Phillips, P.H. Elzer, R.M. Roop, and K.M. Peterson. 1994. pBBR1MCS: a broad-host-range cloning vector. BioTechniques 16:800-802.

77.Kristensen, C.S., L. Eberl, J.M. SanchezRomero, M. Givskov, S. Molin, and V. de Lorenzo. 1995. Site-specific deletions of chromosomally located DNA segments with the multimer resolution system of broad-hostrange plasmid RP4. J. Bacteriol. 177:52-58.

78.Labes, M., A. Puhler, and R. Simon. 1990. A new family of RSF1010-derived expression and lac-fusion broad-host- range vectors for gram-negative bacteria. Gene 89:37-46.

79.Layton, A.C., M. Muccini, M.M. Ghosh, and G.S. Sayler. 1998. Construction of a bioluminescent reporter strain to detect polychlorinated biphenyls. Appl. Environ. Microbiol. 64:5023-5026.

80.Leemans, R., E. Remaut, and W. Fiers. 1987. A broad-host-range expression vector based on the $\mathrm{pL}$ promoter of coliphage $\lambda$ : regulated synthesis of human interleukin 2 in Erwinia and Serratia species. J. Bacteriol. 169:1899-1904.

81.Lindgren, P.B., R. Frederick, A.G. Govindarajan, N.J. Panopoulos, B.J. Staskawicz, and S.E. Lindow. 1989. An ice nucleation reporter gene system: identification of inducible pathogenicity genes in Pseudomonas syringae pv. phaseolicola. EMBO J. 8:1291-1301.

82.Mahan, M.J., D.M. Heithoff, R.L. Sinsheimer, and D.A. Low. 2000. Assessment of bacterial pathogenesis by analysis of gene expression in the host. Annu. Rev. Genet. 34 139-164.

83.Marsch-Moreno, R., G. Hernandez-Guzman, and A. Alvarez-Morales. 1998. pTn5cat: a Tn5-derived genetic element to facilitate insertion mutagenesis, promoter probing, physical mapping, cloning, and marker exchange in phytopathogenic and other gramnegative bacteria. Plasmid 39:205-214.

84.Masters, C.I. and K.W. Minton. 1992. Promoter probe and shuttle plasmids for Deinococcus radiodurans. Plasmid 28:258-261.

85.Matthysse, A.G., S. Stretton, C. Dandie, N.C. McClure, and A.E. Goodman. 1996. Construction of GFP vectors for use in gramnegative bacteria other than Escherichia coli. FEMS Microbiol. Lett. 145:87-94.

86. Meima, R. and M.E. Lidstrom. 2000. Characterization of the minimal replicon of a cryptic Deinococcus radiodurans SARK plasmid and development of versatile Escherichia coli$D$. radiodurans shuttle vectors. Appl. Environ. Microbiol. 66:3856-3867.

87.Mermod, N., J.L. Ramos, P.R. Lehrbach, and K.N. Timmis. 1986. Vector for regulated expression of cloned genes in a wide range of gram-negative bacteria. J. Bacteriol. 167:447454.

88.Merriman, T.R. and I.L. Lamont. 1993 Construction and use of a self-cloning promoter probe vector for gram-negative bacteria. Gene 126:17-23.

89.Miller, V.L. and J.J. Mekalanos. 1988. A novel suicide vector and its use in construction of insertion mutations: osmoregulation of outer membrane proteins and virulence determinants in Vibrio cholerae requires toxR. J. Bacteriol. 170:2575-2583.

90.Molin, S., L. Boe, L.B. Jensen, C.S. Kristensen, M. Givskov, J.L. Ramos, and A.K. Bej. 1993. Suicidal genetic elements and their use in biological containment of bacteria. Annu. Rev. Microbiol. 47:139-166.

91.Molina, L., C. Ramos, M.C. Ronchel, S. Molin, and J.L. Ramos. 1998. Construction of an efficient biologically contained Pseudomonas putida strain and its survival in outdoor assays. Appl. Environ. Microbiol. 64:20722078.

92.Morales, V.M., A. Backman, and M. Bagdasarian. 1991. A series of wide-host-range low-copy-number vectors that allow direct screening for recombinants. Gene 97:39-47.

93.Munthali, M., K.N. Timmis, and E. Diaz. 1996. Restricting the dispersal of recombinant DNA: design of a contained biological catalyst. Biotechnology (NY) 14:189-191.

94.Newman, J.R. and C. Fuqua. 1999. Broadhost-range expression vectors that carry the Larabinose-inducible Escherichia coli araBAD promoter and the araC regulator. Gene 227:197-203.

95.Normander, B., N.B. Hendriksen, and O. Nybroe. 1999. Green fluorescent proteinmarked Pseudomonas fluorescens: localization, viability, and activity in the natural barley rhizosphere. Appl. Environ. Microbiol. 65: 4646-4651.

96.Ouahrani-Bettache, S., F. Porte, J. Teyssier, J.P. Liautard, and S. Kohler. 1999. pBBR1-GFP: a broad-host-range vector for prokaryotic promoter studies. BioTechniques 26:620-622.

97.Palomares, A.J., M.A. DeLuca, and D.R. Helinski. 1989. Firefly luciferase as a reporter enzyme for measuring gene expression in vegetative and symbiotic Rhizobium meliloti and other gram-negative bacteria. Gene 81:55-64.

98.Panke, S., J.M. Sanchez-Romero, and V. de Lorenzo. 1998. Engineering of quasi-natural Pseudomonas putida strains for toluene metabolism through an ortho-cleavage degradation pathway. Appl. Environ. Microbiol. 64:748-751.

99.Prosser, J.I. 1994. Molecular marker systems for detection of genetically engineered micro-organisms in the environment. Microbiology 140:5-17.

100.Raaijmakers, J.M., W. Bitter, H.L. Punte, P.A. Bakker, P.J. Weisbeek, and B. Schippers. 1994. Siderophore receptor PupA as a marker to monitor wild-type Pseudomonas putida WCS358 in natural environments. Appl. Environ. Microbiol. 60:1184-1190.

101.Ramos, J.L., E. Diaz, D. Dowling, V. de Lorenzo, S. Molin, F. O'Gara, C. Ramos, 
and K.N. Timmis. 1994. The behavior of bacteria designed for biodegradation. Biotechnology (NY) 12:1349-1356.

102.Rattray, E.A., J.I. Prosser, L.A. Glover, and K. Killham. 1995. Characterization of rhizosphere colonization by luminescent $E n$ terobacter cloacae at the population and single-cell levels. Appl. Environ. Microbiol. 61:2950-2957.

103.Reeve, W.G., R.P. Tiwari, P.S. Worsley, M.J. Dilworth, A.R. Glenn, and J.G. Howieson. 1999. Constructs for insertional mutagenesis, transcriptional signal localization and gene regulation studies in root nodule and other bacteria. Microbiology 145:13071316.

104.Ripp, S., D.E. Nivens, C. Werner, and G.S. Sayler. 2000. Bioluminescent most-probablenumber monitoring of a genetically engineered bacterium during a long-term contained field release. Appl. Microbiol. Biotechnol. 53:736-741.

105.Rist, M. and M.A. Kertesz. 1998. Construction of improved plasmid vectors for promoter characterization in Pseudomonas aeruginosa and other gram-negative bacteria. FEMS Microbiol. Lett. 169:179-183.

106.Rothmel, R.K., A.M. Chakrabarty, A. Berry, and A. Darzins. 1991. Genetic systems in Pseudomonas. Methods Enzymol. 204:485-514.

107.Saint, C.P., S. Alexander, and N.C. McClure. 1995. pTIM3, a plasmid delivery vector for a transposon-based inducible marker gene system in gram-negative bacteria. Plasmid 34:165-174.

108.Sanchez-Romero, J.M., R. Diaz-Orejas, and V. de Lorenzo. 1998. Resistance to tellurite as a selection marker for genetic manipulations of Pseudomonas strains. Appl. Environ. Microbiol. 64:4040-4046.

109.Sasakawa, C. and M. Yoshikawa. 1987. A series of Tn5 variants with various drug-resistance markers and suicide vector for transposon mutagenesis. Gene 56:283-288.

110.Schweizer, H.P. 1991. Escherichia-Pseudomonas shuttle vectors derived from pUC18/ 19. Gene 97:109-121.

111.Schweizer, H.P. 1991. Improved broad-hostrange lac-based plasmid vectors for the isolation and characterization of protein fusions in Pseudomonas aeruginosa. Gene 103:87-92.

112.Schweizer, H.P. 1992. Allelic exchange in Pseudomonas aeruginosa using novel ColE1type vectors and a family of cassettes containing a portable oriT and the counter-selectable Bacillus subtilis sacB marker. Mol. Microbiol. 6:1195-1204.

113.Schweizer, H.P. and T.T. Hoang. 1995. An improved system for gene replacement and xylE fusion analysis in Pseudomonas aeruginosa. Gene 158:15-22.

114.Sessitsch, A., K.J. Wilson, A.D. Akkermans, and W.M. de Vos. 1996. Simultaneous detection of different Rhizobium strains marked with either the Escherichia coli gus A gene or the Pyrococcus furiosus celB gene. Appl. Environ. Microbiol. 62:4191-4194.

115.Shalom, G., J.G. Shaw, and M.S. Thomas. 2000. pGSTp: an IVET-compatible promoter probe vector conferring resistance to trimethoprim. BioTechniques 29:954-6, 958.
116.Simon, R., M. O'Connell, M. Labes, and A. Puhler. 1986. Plasmid vectors for the genetic analysis and manipulation of rhizobia and other gram-negative bacteria. Methods Enzymol. 118:640-659.

117.Skrzypek, E., P.L. Haddix, G.V. Plano, and S.C. Straley. 1993. New suicide vector for gene replacement in Yersinia and other gram-negative bacteria. Plasmid 29:160-163.

118.Slauch, J.M. and A. Camilli. 2000. IVET and RIVET: use of gene fusions to identify bacterial virulence factors specifically induced in host tissues. Methods Enzymol. 326:73-96

119.Slauch, J.M., M.J. Mahan, and J.J. Mekalanos. 1994. In vivo expression technology for selection of bacterial genes specifically induced in host tissues. Methods Enzymol. 235:481-492.

120.Suarez, A., A. Guttler, M. Stratz, L.H. Staendner, K.N. Timmis, and C.A. Guzman. 1997. Green fluorescent protein-based reporter systems for genetic analysis of bacteria including monocopy applications. Gene 196:69-74.

121.Sukchawalit, R., P. Vattanaviboon, R. Sallabhan, and S. Mongkolsuk. 1999. Construction and characterization of regulated Larabinose-inducible broad host range expression vectors in Xanthomonas. FEMS Microbiol. Lett. 181:217-223.

122.Taghavi, S., H. Delanghe, C. Lodewyckx, M. Mergeay, and D. van der Lelie. 2001. Nickel-resistance-based minitransposons: new tools for genetic manipulation of environmental bacteria. Appl. Environ. Microbiol. 67:1015-1019.

123.Taylor, R.K., C. Manoil, and J.J. Mekalanos. 1989. Broad-host-range vectors for delivery of TnphoA: use in genetic analysis of secreted virulence determinants of Vibrio cholerae. J. Bacteriol. 171:1870-1878.

124.Thomson, V.J., M.K. Bhattacharjee, D.H. Fine, K.M. Derbyshire, and D.H. Figurski. 1999. Direct selection of IS903 transposon insertions by use of a broad-host-range vector: isolation of catalase-deficient mutants of Actinobacillus actinomycetemcomitans. J. Bacteriol. 181:7298-7307.

125.Tibazarwa, C., P. Corbisier, M. Mench, A. Bossus, P. Solda, M. Mergeay, L. Wyns, and D. van der Lelie. 2001. A microbial biosensor to predict bioavailable nickel in soil and its transfer to plants. Environ. Pollut. 113:19-26.

126.Toder, D.S. 1994. Gene replacement in Pseudomonas aeruginosa. Methods Enzymol. 235:466-474.

127.Tsuda, M. and T. Nakazawa. 1993. A mutagenesis system utilizing a Tn1722 derivative containing an Escherichia coli-specific vector plasmid: application to Pseudomonas species. Gene 136:257-262.

128.Valdivia, R.H. and S. Falkow. 1997. Fluorescence-based isolation of bacterial genes expressed within host cells. Science 277:20072011.

129.Valdivia, R.H. and L. Ramakrishnan. 2000. Applications of gene fusions to green fluorescent protein and flow cytometry to the study of bacterial gene expression in host cells. Methods Enzymol. 326:47-73.

130.van der Bij, A.J., A. Letty, W.T. Tucker, and B.J. Lugtenberg. 1996. Plasmid stability in Pseudomonas fluorescens in the rhizosphere. Appl. Environ. Microbiol. 62:10761080.

131.van der Lelie, D., P. Corbisier, W. Baeyens, S. Wuertz, L. Diels, and M. Mergeay. 1994. The use of biosensors for environmental monitoring. Res. Microbiol. 145:67-74.

132.Waterhouse, R.N., D.J. Silcock, H.L. White, H.K. Buhariwalla, and L.A. Glover. 1993. The cloning and characterization of phage promoters, directing high expression of luciferase in Pseudomonas syringae pv. phaseolicola, allowing single cell and microcolony detection. Mol. Ecol. 2:285-293.

133.Watson, A.A., R.A. Alm, and J.S. Mattick. 1996. Construction of improved vectors for protein production in Pseudomonas aeruginosa. Gene 172:163-164.

134.Weng, S.F., M.Y. Shieh, F.Y. Lai, Y.Y. Shao, J.W. Lin, and Y.H. Tseng. 1996. Construction of a broad-host-range promoterprobing vector and cloning of promoter fragments of Xanthomonas campestris. Biochem. Biophys. Res. Commun. 228:386-390.

135.West, S.E., H.P. Schweizer, C. Dall, A.K. Sample, and L.J. Runyen-Janecky. 1994. Construction of improved EscherichiaPseudomonas shuttle vectors derived from pUC18/19 and sequence of the region required for their replication in Pseudomonas aeruginosa. Gene 148:81-86.

136.Wong, S.M. and J.J. Mekalanos. 2000. Genetic footprinting with mariner-based transposition in Pseudomonas aeruginosa. Proc. Natl. Acad. Sci. USA 97:10191-10196.

\section{Address correspondence to:}

John Davison

Laboratoire de Biologie Cellulaire

Institut National de la Recherche

Agronomique (INRA)

Route de St. Cyr

Versailles F-78260, France

e-mail: davisona@jouy.inra.fr

For reprints of this or any other article, contact Reprints@BioTechniques.com 